\title{
Table of the Bankruptcy Code (Title 11, United States Code), as amended
}

Ch 1 (General Provisions) .................................................... 37, 38

Ch 3 (Case Administration) ............................................... 37, 38, 174

Ch 5 (Creditors, Debtors, and the Estate) ............................... 37, 38

Ch 7 (Liquidation) ................... ix, x, xi, 2, 8, 9, 10-14, 19, 25, 32, 37,

$39,40,47,49,51,55,56,59,67,80-82,83-86,87-90,91-94$, $96,97,98,99,118,119,120,122,125,126,128,141,142,143$,

$\mathrm{Ch} 7(\mathrm{I})$ $146,157,168,171,174,176$

Ch 7(II)

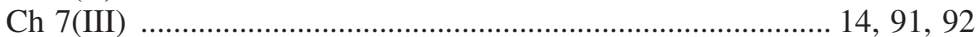

Ch 7(IV) ........................................................................... 14, 92, 93

Ch 7(V) ..................................................................... 93, 94

Ch 9 (Municipal bankruptcy) ............................................. 37, 67

Ch 11 (Reorganization) .................... ix, x, xi, 2, 7, 8, 9, 14-19, 25, 34, $37,40,48,49,51,55,56,59,60,61,66,67,69,80,82,86,89$, 93, 94, 96-100, 101-114, 115, 118, 119, 120, 122, 125, 126, 128, $130,131,132,135,136,137,138,139,141,143,146,150,157$, $158,161,162,163,164,165,166,167,168,169,170,171,183$, $185-7$

Ch 11(I, ss 1101-1114) ...................................................................... 98

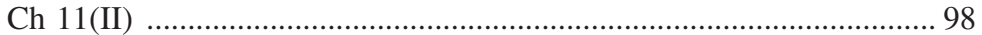

Ch 11(III) .............................................................................. 98

Ch 11(IV, ss 1161-1174) ....................................................... 19, 98

Ch 11(V, ss 1181-1195) ......................................................... 173-181

Ch 12 .............................................................. 9, 37, 176, 180

Ch 13 ....................................................................... 9, 176, 180

Ch 15 (Transnational business bankruptcy) ................ ix, 32, 37, 183-7

Ch 21

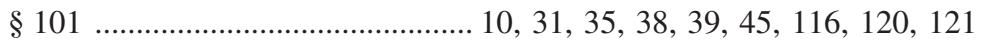

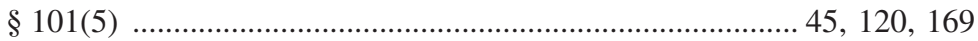

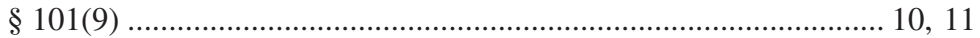

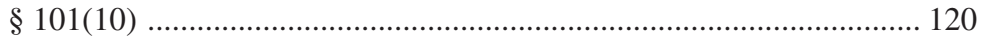

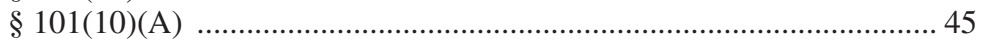

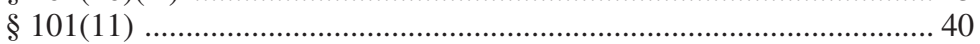

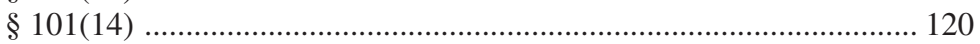


$\S 101(16)$ 47,120

$\S 101(17)$ 120

$\S 101(18)(\mathrm{B})$ 9

$\S 101(19 \mathrm{~A})(\mathrm{B})$ 9

$\S 101(20)$ 31

$\S 101(22)$ 13

$\S 101(31)$ 70,121

$\S 101(32)$ 70

$\S 101(32)(\mathrm{A})$ 75

$\S 101(41)$ 10,175

$\S 101(44)$ 12

$\S 101(51 \mathrm{C})$ 174

$\S 101(51 \mathrm{D})$ $116,174-6$

$\S 101(54)$

$\S 101(\mathrm{c})$ 121

$\S 102$ 49

§ 102(3) 48

$\S 102(6)$ 19

$\S 104$ 32

§ 103(a) 37

$\S 103(\mathrm{f})$ 37

$\S 104$ 73

$\S 105$ (a)

$\S 109$ 42

$\S 109$ (a) 38,93

$\S 109$ (b) 10,12

\$ 109(b)(2) 12,14

$\S 109$ (b)(3) 13,14

$\S 109$ (d)

§ 301 14

§ 301(a) 35,38

§ 301(b) 19, 35

$\S 302$ 19

$\S 303$ 38

§ 303(a) 38

$\S 303$ (b) 31

$\S 303(\mathrm{~b})(3)(\mathrm{A})$. 31

$\S 303$ (b)(4) 32

$\S 303(d)$ 32

$\S 303$ (f) 32

§ 303(h) 32

§ 303(i) 32

$\S 307$ 33

$\S 308$ 37

$\S \S 321-325$ 


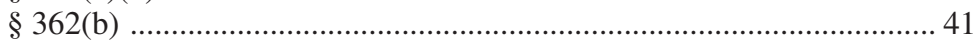

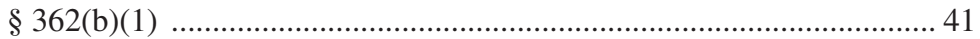

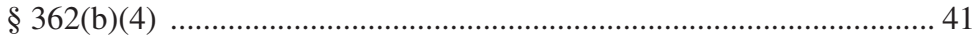

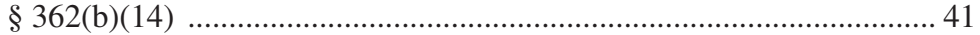

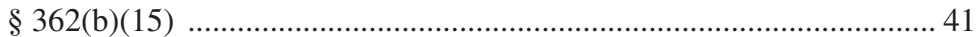

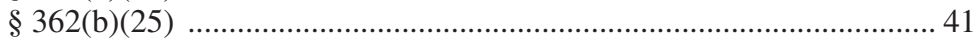

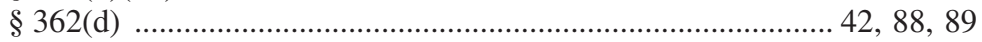

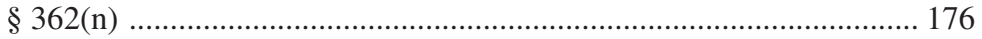

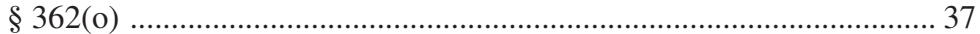

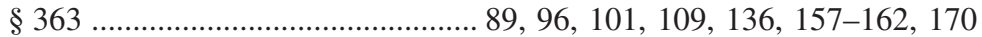

$\S 363(b)$ $97,101,158,159$

$\S 363(b)(1)$ 158 


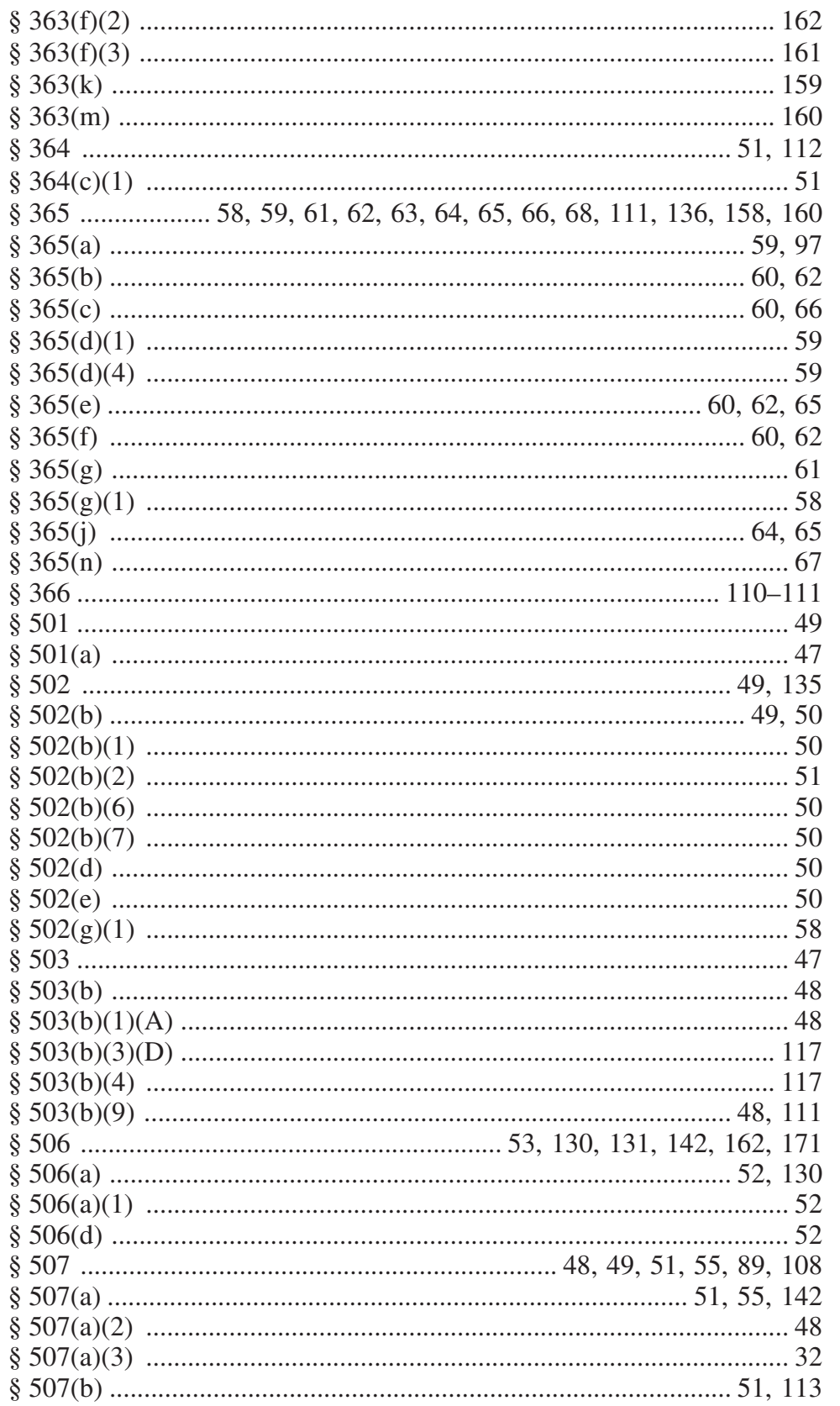




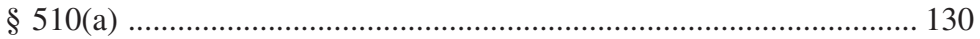

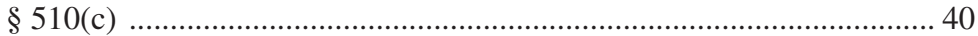

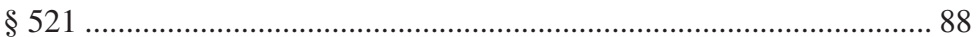

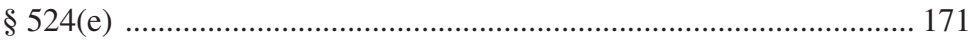

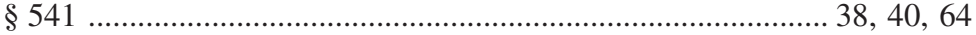

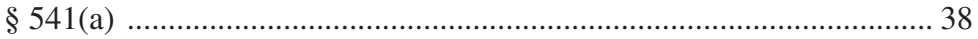

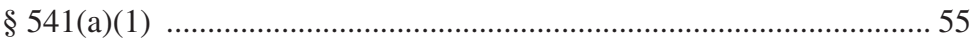

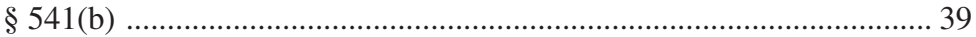

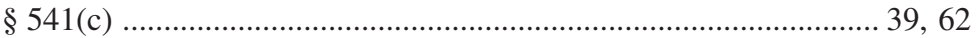

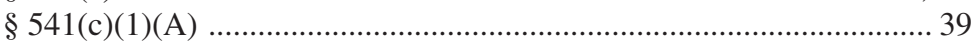

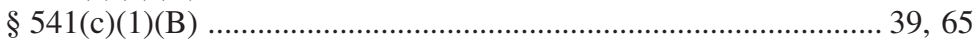

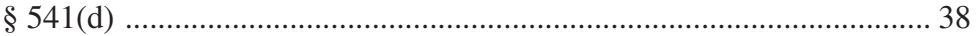

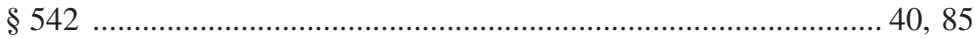

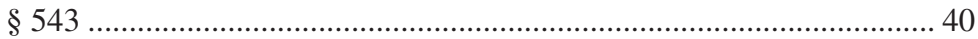

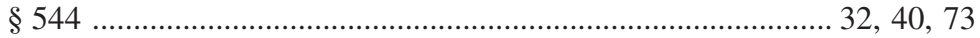

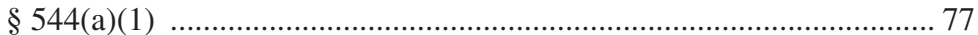

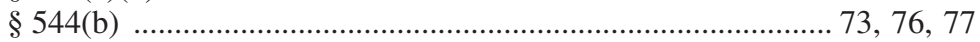

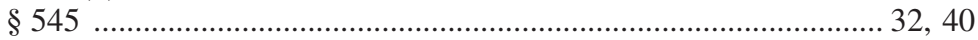

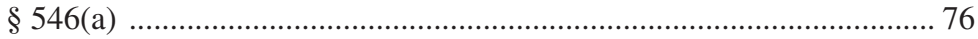

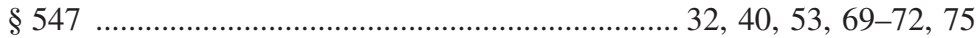

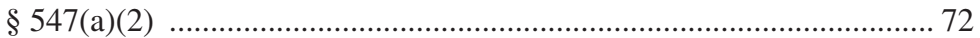

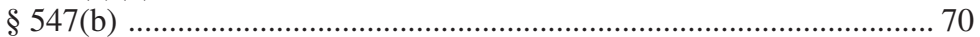

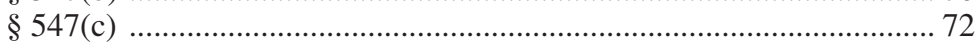

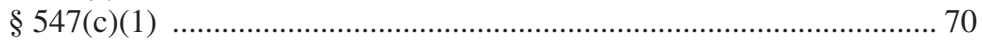

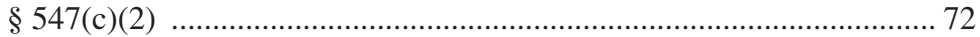

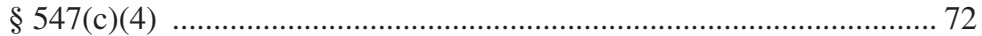

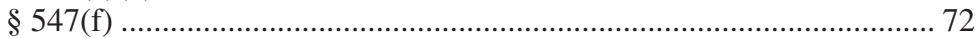

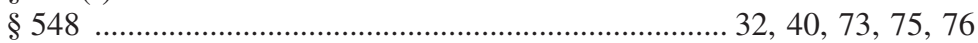

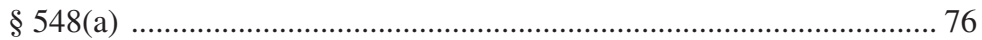

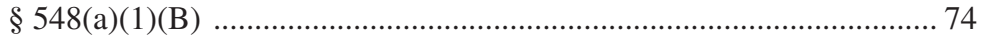

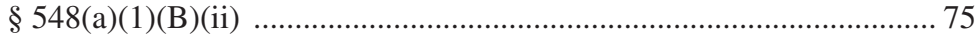

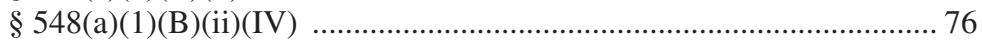

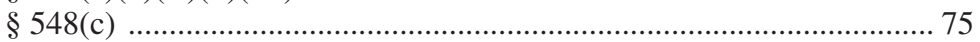

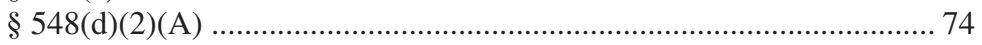

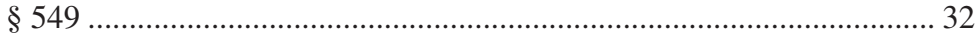

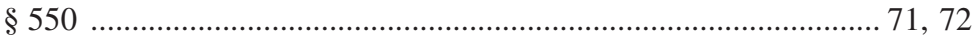

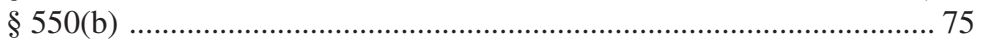

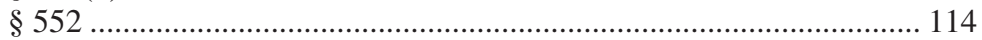

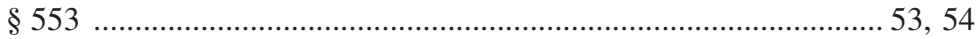

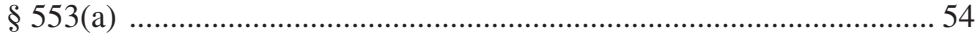

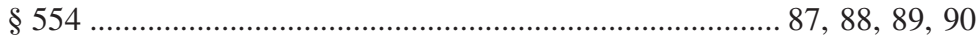

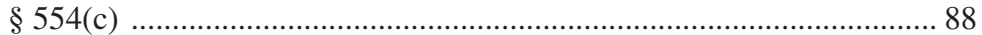

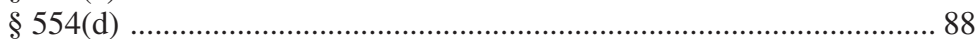

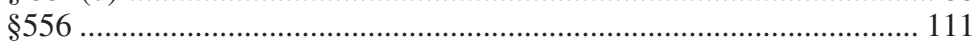

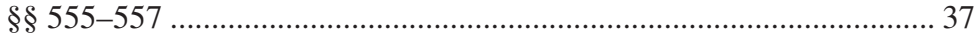




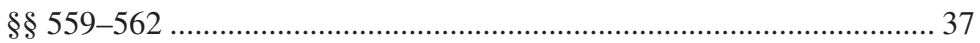

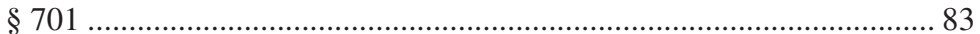

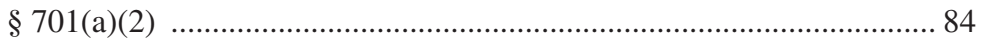

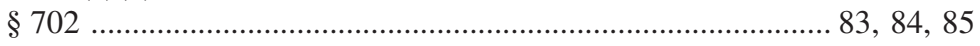

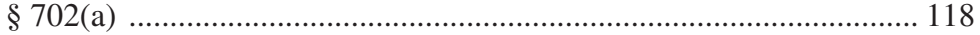

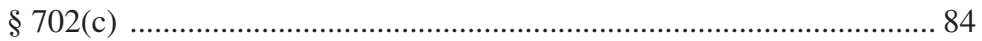

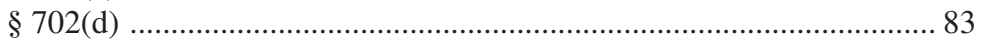

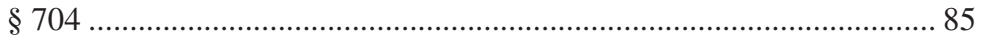

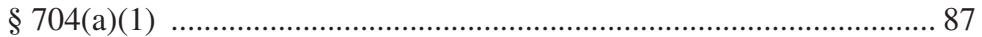

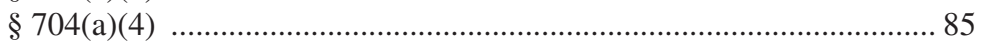

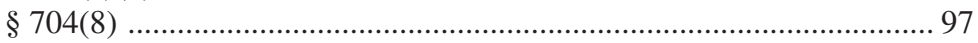

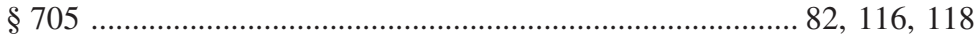

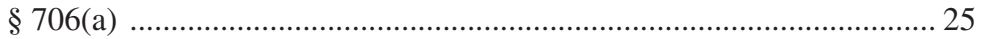

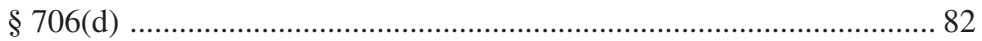

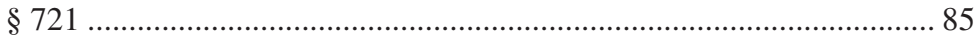

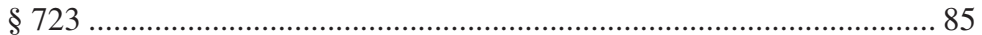

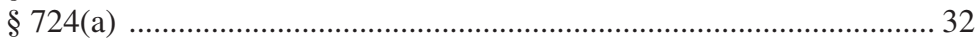

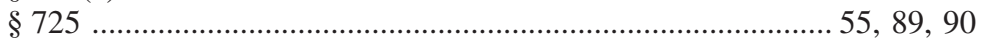

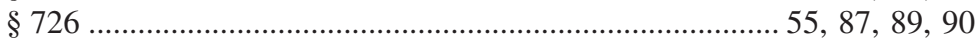

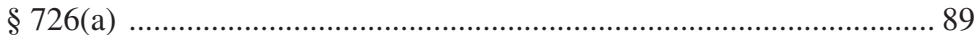

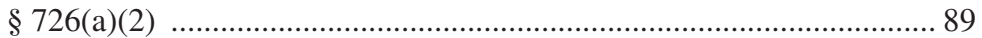

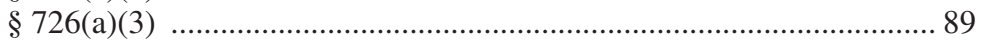

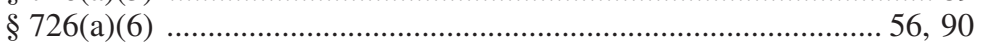

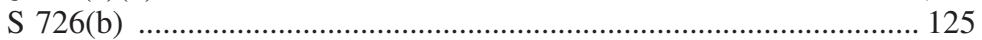

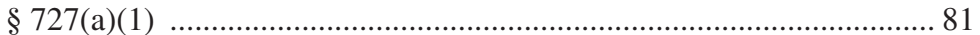

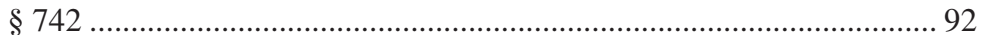

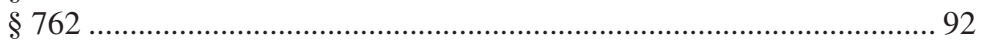

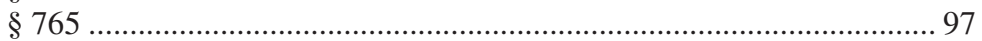

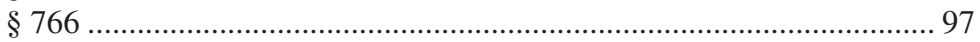

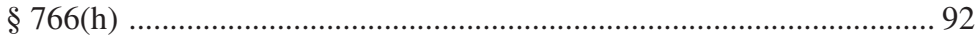

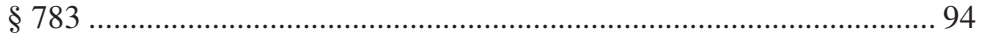

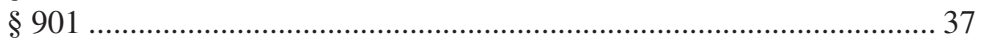

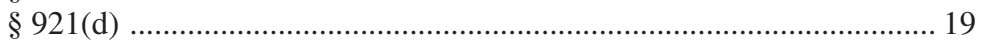

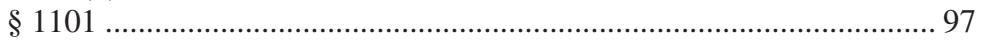

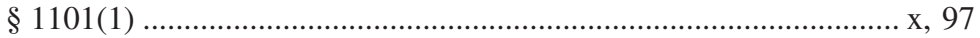

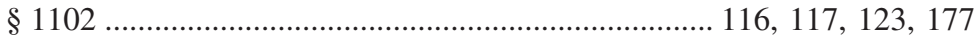

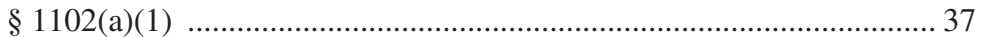

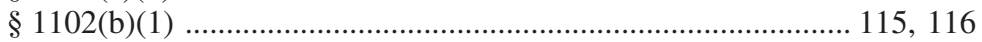

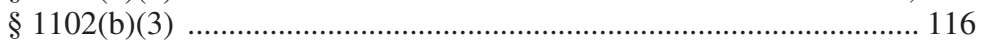

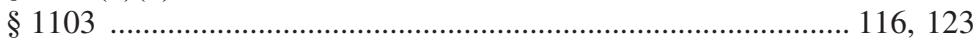

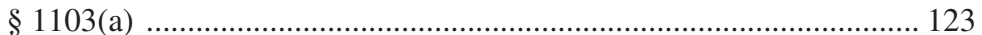

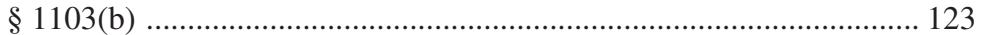

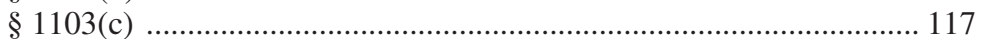

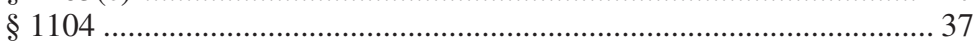

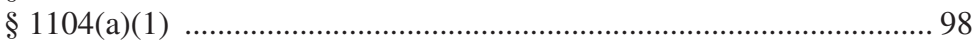




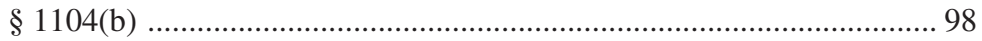

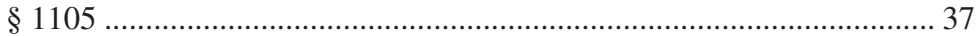

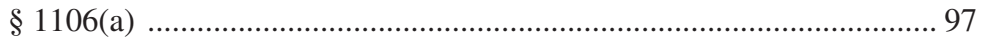

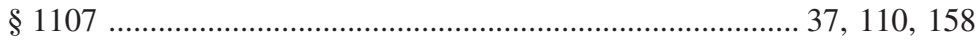

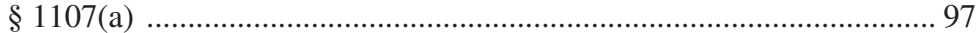

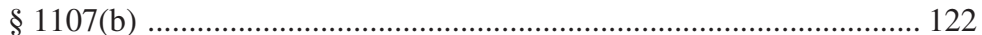

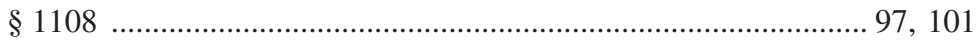

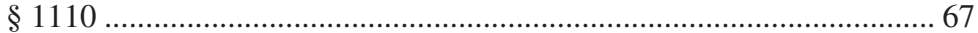

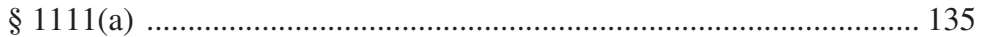

$\S 1111(\mathrm{~b}) \ldots \ldots \ldots \ldots \ldots \ldots \ldots \ldots \ldots \ldots \ldots . .130,131,132,142,153,154,171,178$

§ 1111(b)(1) ................................................................. 130, 131

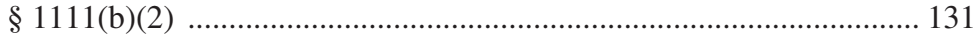

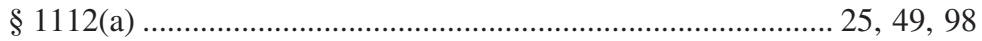

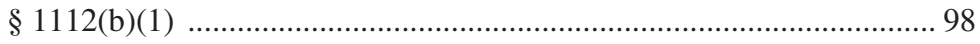

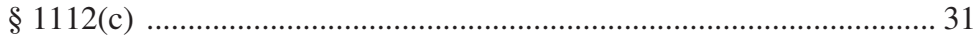

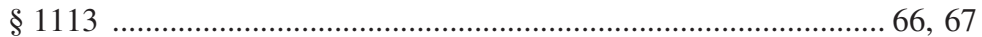

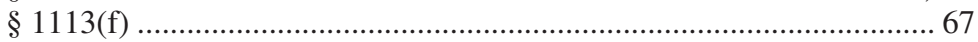

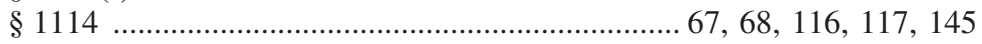

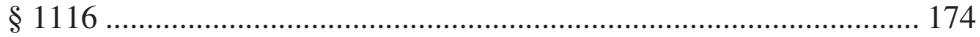

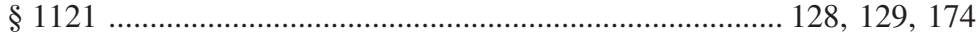

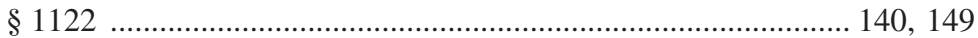

$\S 1122$ (a) ............................................................................ 130

$\S 1122$ (b) ......................................................................... 130, 143

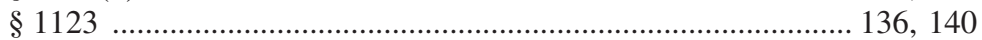

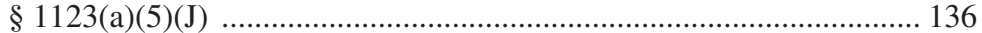

§ 1123(a) .......................................................................... 129, 134

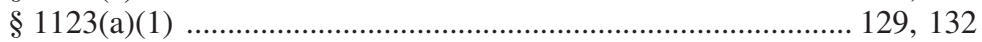

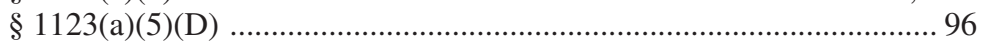

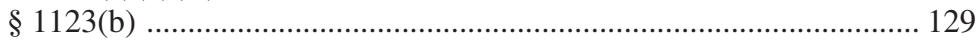

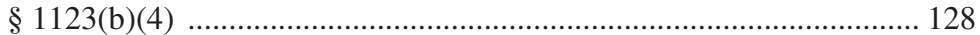

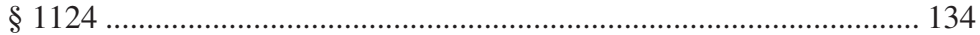

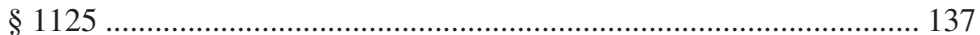

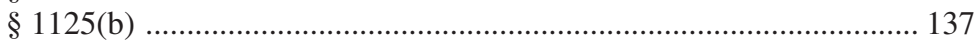

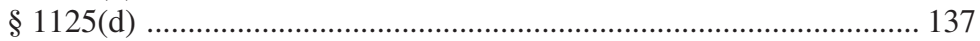

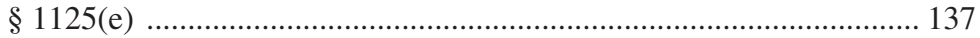

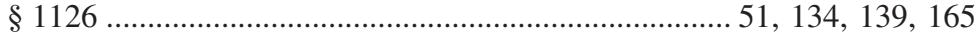

§ $1126(\mathrm{c})$..................................................... 134, 135, 139, 144, 164

$\S 1126(\mathrm{e})$..................................................................... 135, 164

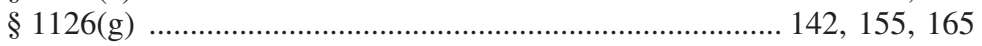

\$ 1129 ...................................................................... 139, 161

§1129(a) ............. 139, 140, 145, 146, 147, 148, 149, 156, 167, 177-9

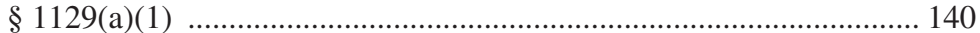

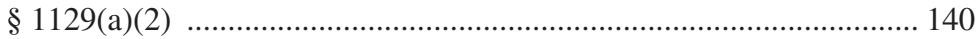

\$ $1129(\mathrm{a})(3)$............................................................... 140, 144

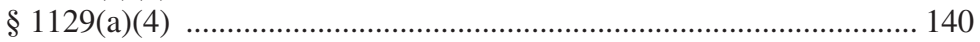




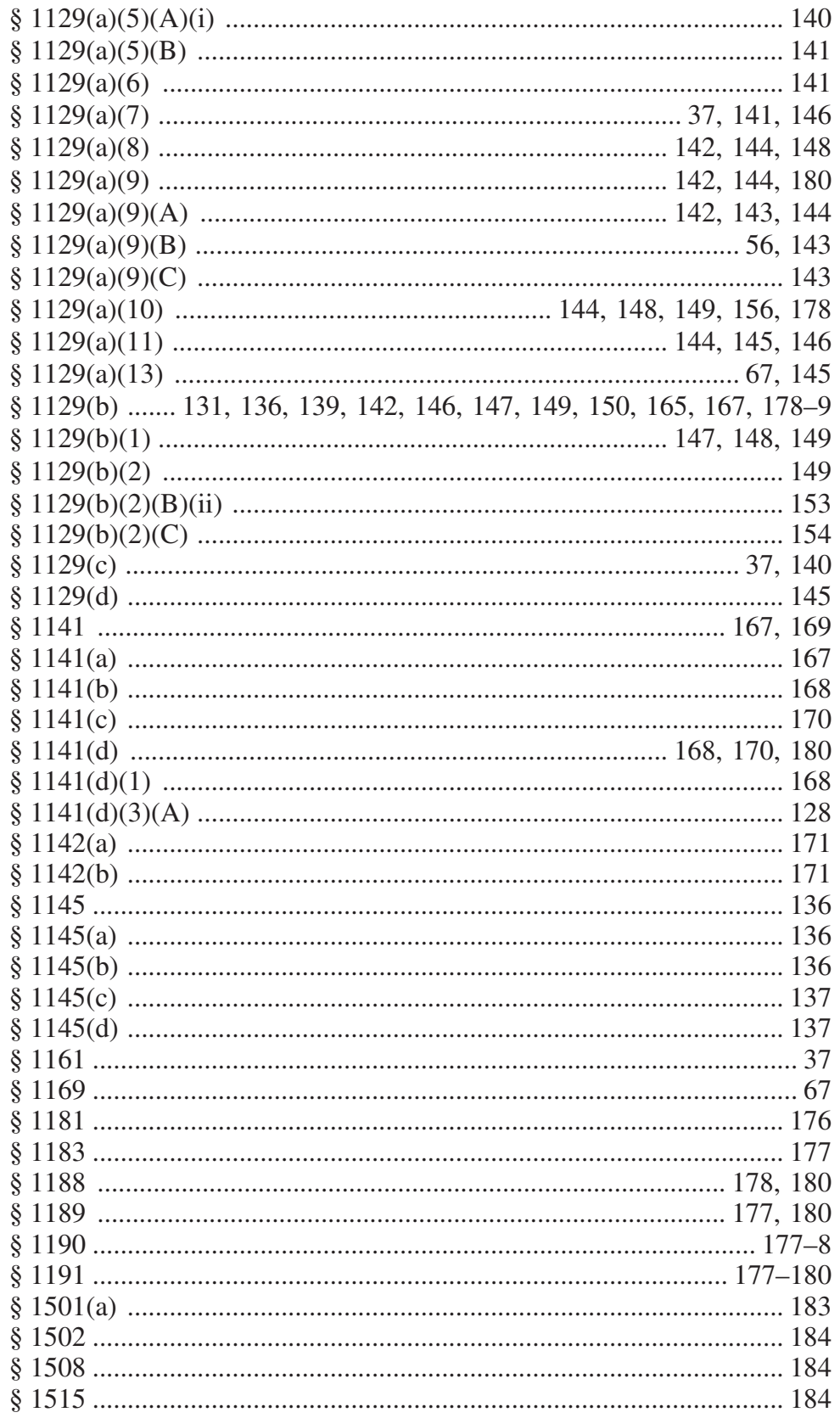




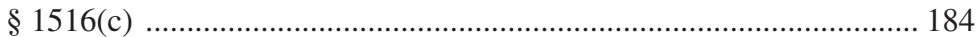

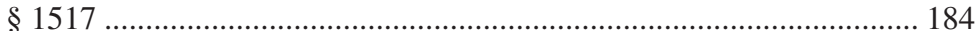

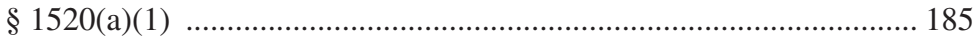

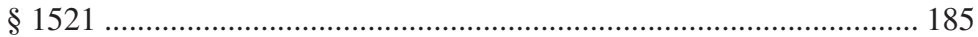


Stephen J. Lubben - 9781800379206 Downloaded from PubFactory at $04 / 26 / 2023$ 10:09:33AM 